\title{
Treating Alzheimer Disease: Is Diet and Exercise more Effective than Small Molecule Therapy?
}

Kayla C. Castellani ${ }^{1}$, Elizabeth A. Perry ${ }^{2}$, George Perry ${ }^{2 *}$ and Rudy J. Castellani ${ }^{3}$

${ }^{1}$ College of Osteopathic Medicine, Michigan State University, East Lansing, Michigan, USA

${ }^{2}$ College of Sciences, University of Texas, San Antonio, Texas, USA

${ }^{3}$ Division of Neuropathology, University of Maryland, Baltimore, Maryland, USA

As Alzheimer's disease (AD) therapeutic research continues to pursue small molecule targeting, disease modifying therapy remains elusive [1]. Indeed, despite a wide array of pharmacologic agents at our disposal and the design and completion of dozens of clinical trials targeting Amyloid-beta $(\mathrm{A} \beta)$, no approach has shown any progress whatsoever in ameliorating the disease process, and affected patients continue to suffer and expire on the same cognitive trajectory as they have since the dawn of the species. One major defect in the so-called amyloid cascade hypothesis is that the hypothesis itself, as well as essentially all experimental modeling, is derived entirely from Mendelian conditions, i.e. familial autosomal dominant disease [2]. Such conditions are not only exceedingly rare (total number of amyloid $\beta$ protein precursor mutation kindreds in the world number less than 100 , for example), but encompass lifelong defects in cellular physiology. The repeated failures in sporadic $\mathrm{AD}$ therapy may simply be due to the inapplicability of this small molecule construct to something as complex as age-related sporadic neurodegeneration. Indeed, an in depth analysis of clinicopathological correlations in sporadic disease reveals that the pathology of $\mathrm{AD}$ (and a spectrum of chronic diseases), is indicative of a response to the aging environment, possibly even a productive response, in which case targeting such a response would be ineffective at best, and deleterious at worst. This is to say nothing of the empirical problem with targeting a single small molecule within the scope of the neuronal proteome, comprised of many thousands of protein transcripts at any give time.

It may be time to embrace an aggressively holistic approach to such a disease process that is intimately intertwined with age and the simple passage of time. The many risk factors for sporadic $\mathrm{AD}$, comprised for example of cerebrovascular disease, diabetes mellitus, head trauma and neuroinflammation, neuroendocrinology, and transition metals, suggest that $\mathrm{AD}$ is a whole organism disorder that cannot be addressed by any singular construct, least of all lesion targeting. The role of a healthy multi-nutrient diet [3], as both a direct (e.g. antioxidants) and indirect (e.g. reducing obesity and atherosclerosis related risk factors) means of prevention and treatment is already as effective as the most sophisticated of clinical trials to date, and probably more so. Moreover, as the hormesis concept becomes better developed, a judicious exercise program may similarly be of measurable, whole organism benefit, just as hormetic kinetics of $\mathrm{A} \beta$ may be operant as a potential factor in the physiology-pathology continuum [4]. Such processes may further underlie the concept of mental "activity," and the influence of brain usage in the form of educational attainment, as a means of defense against cognitive decline, associated with a given pathological load. At present, it appears that effective therapy for $\mathrm{AD}$ associated neurodegeneration is in the distant future and may well take a number of generations, as well as a paradigm shift for measurable progress to occur. Nevertheless, the benefits of something as simple as a healthy diet, mental activity, and a regular exercise program, in combating oxidative stress, neuroinflammation, and the aging process has already proven beneficial to both the quality and quantity of life. Small molecule therapy based on the amyloid cascade model has achieved neither, and unless a different paradigm is pursued, likely never will.

\section{References}

1. Castellani RJ, Perry G (2012) Pathogenesis and Disease-modifying Therapy in Alzheimer's Disease: The Flat Line of Progress. Arch Med Res.

2. Castellani RJ, Lee HG, Zhu X, Perry G, Smith MA (2008) Alzheimer disease pathology as a host response. J Neuropathol Exp Neurol 67: 523-531.

3. Broersen LM, Kuipers AA, Balvers M, van Wijk N, Savelkoul PJ, et al. (2013) A Specific Multi-Nutrient Diet Reduces Alzheimer-Like Pathology in Young Adult AßPPswe/PS1dE9 Mice. J Alzheimers Dis 33: 177-190.

4. Morley JE, Farr SA (2012) Hormesis and amyloid- $\beta$ protein: physiology or pathology? J Alzheimers Dis 29: 487-492.
*Corresponding author: George Perry Ph.D, Professor, College of Sciences, University of Texas, San Antonio, Texas, USA, Tel: 210-458-4450; Fax: 210-4584445; E-mail: george.perry@utsa.edu

Received December 06, 2012; Accepted December 08, 2012; Published December 11, 2012

Citation: Castellani KC, Perry EA, Perry G, Castellani RJ (2013) Treating Alzheimer Disease: Is Diet and Exercise more Effective than Small Molecule Therapy? J Membra Sci Technol 3: e111. doi:10.4172/2155-9589.1000e111

Copyright: (c) 2013 Castellani KC, et al. This is an open-access article distributed under the terms of the Creative Commons Attribution License, which permits unrestricted use, distribution, and reproduction in any medium, provided the original author and source are credited. 